Document downloaded from:

http://hdl.handle.net/10251/147542

This paper must be cited as:

Vila, C.; Rendón-Patiño, A.; Montesinos-Magraner, M.; Blay, G.; Muñoz Roca, MDC.; Pedro, J. (2018). Organocatalytic Enantioselective Functionalization of Hydroxyquinolines through an Aza-Friedel-Crafts Alkylation with Isatin-derived Ketimines. Advanced Synthesis \& Catalysis. 360(5):859-864. https://doi.org/10.1002/adsc.201701217

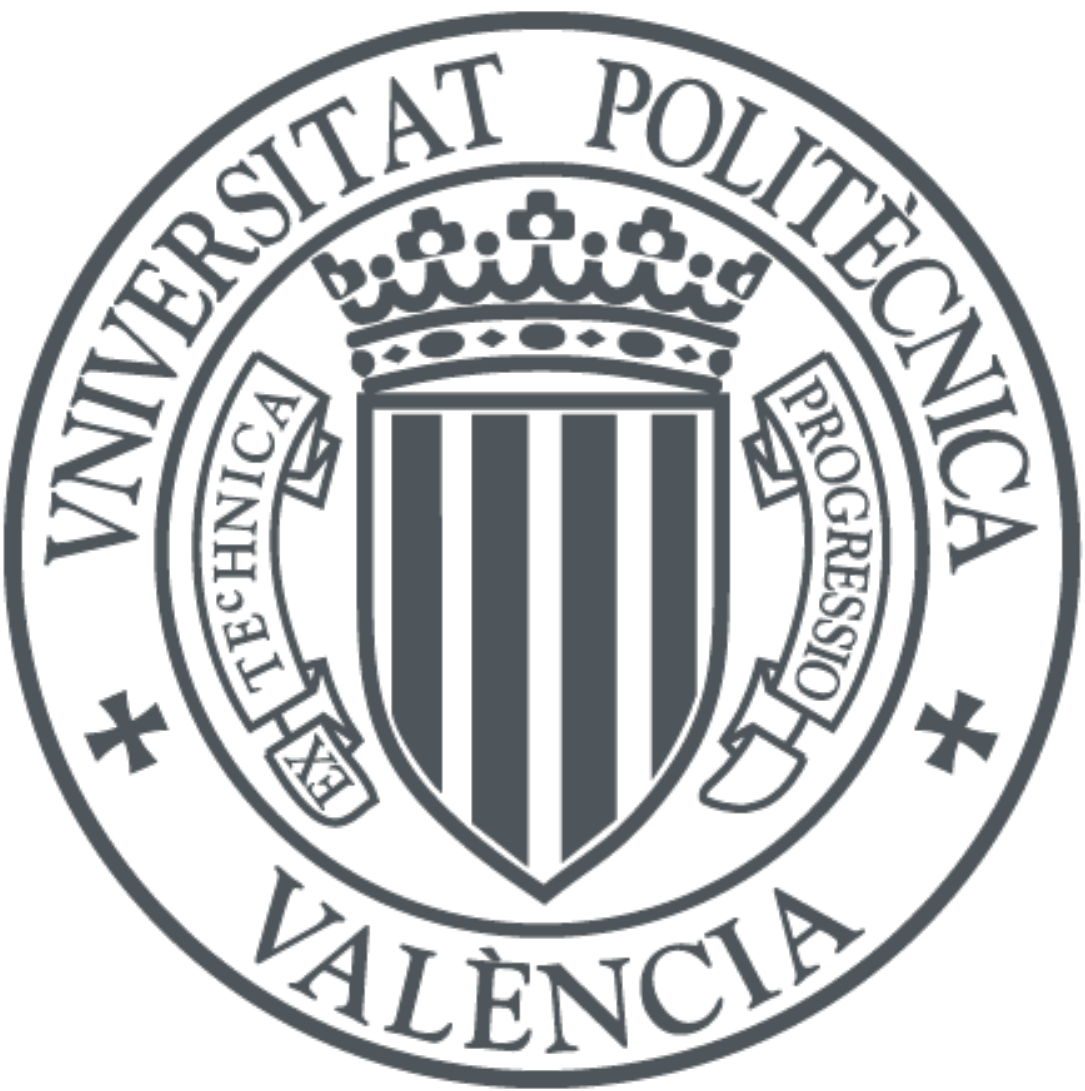

The final publication is available at

https://doi.org/10.1002/adsc.201701217

Copyright John Wiley \& Sons

Additional Information 


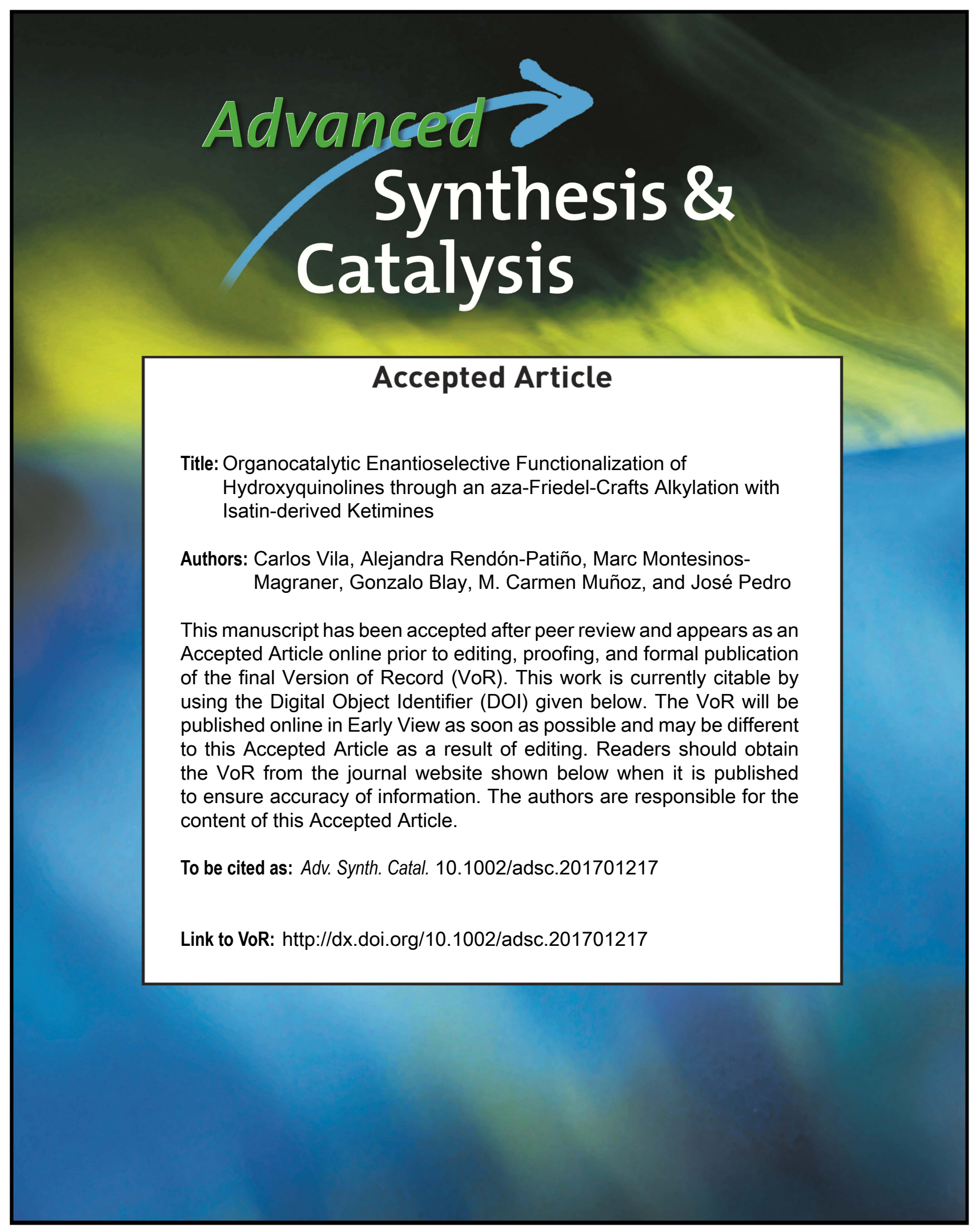




\title{
Organocatalytic Enantioselective Functionalization of Hydroxyquinolines through an Aza-Friedel-Crafts Alkylation with Isatin-derived Ketimines
}

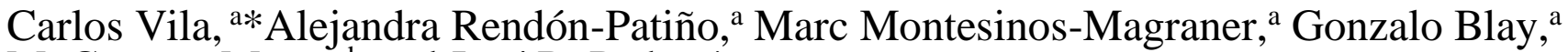 \\ M. Carmen Muñoz and José R. Pedro ${ }^{\mathrm{a} *}$ \\ a Departament de Química Orgànica, Facultat de Química, Universitat de València, Dr. Moliner 50, 46100 Burjassot, \\ València (Spain). E-mail: carlos.vila@uv.es, jose.r.pedro@uv.es \\ b Departament de Física Aplicada, Universitat Politècnica de València, Camino de Vera s/n, 46022 València (Spain)
}

Received: ((will be filled in by the editorial staff))

Supporting information for this article is available on the WWW under http://dx.doi.org/10.1002/adsc.201\#\#\#\#\#\#.((Please delete if not appropriate))

\begin{abstract}
A highly enantioselective addition of hydroxyquinolines to isatin-derived ketimines has been realized using a quinine-derived thiourea organocatalyst. The reaction affords chiral 3-amino-2-oxindoles bearing a quinoline moiety with a quaternary stereocenter in high yields (up to 98\%) and excellent enantioselectivities (up to 99\%). Moreover, we can extend this methodology for the enantioselective functionalization of 5hydroxyisoquinoline. This methodology represents, to the best of our knowledge, the first enantioselective addition of hydroxyquinolines to imines.
\end{abstract}

Keywords: asymmetric organocatalysis ; Friedel-Crafts reaction; isatin-derived ketimines ; quinoline; thiourea

Nitrogen-containing aromatic heterocycles are ubiquitous in agrochemicals, pharmaceuticals and natural products. ${ }^{[1]}$ Therefore, the synthesis of chiral nitrogen heterocycles represents a hot topic in organic chemistry due to the great synthetic and industrial interest of such compounds. In this context, quinoline $^{[2]}$ or 1-aza-naphthalene is one of the most important aza-aromatic compounds because of the wide range of biological activities of their derivatives. The quinoline scaffold is present in numerous natural products, ${ }^{[3]}$ such as the alkaloid quinine used to treat malaria and babesiosis, or its diastereoisomer quinidine with antiarrhythmic activity; quinoline is also present in synthetic drugs such as primaquine, an alternative medication to treat and prevent malaria. Quinoline-pyridone hybrids, both natural (camptothecin) as synthetic derivatives (topotecan) present cytotoxic activity and are used as chemotherapeutic agents (Figure 1A).

The ubiquity of the quinoline scaffold has prompted the development of several efficient methodologies for the functionalization of quinolines. ${ }^{[4]}$ In this context, the electrophilic enantioselective functionalization of the quinoline ring has been scarcely studied, in contrast to the nucleophilic functionalization of quinoline ring broadly investigated in the literature. ${ }^{[5]}$ In order to accomplish the electrophilic functionalization of the quinoline carbocyclic ring, we planned to use the activating/directing effects of a hydroxyl group in the carbocyclic ring. ${ }^{[6]}$ This strategy was used by the group of Jørgensen in $2006,{ }^{[7]}$ for the diastereoselective atropoisomeric functionalization at 5 , position of the quinoline core of cupreine derivatives by an amination reaction.

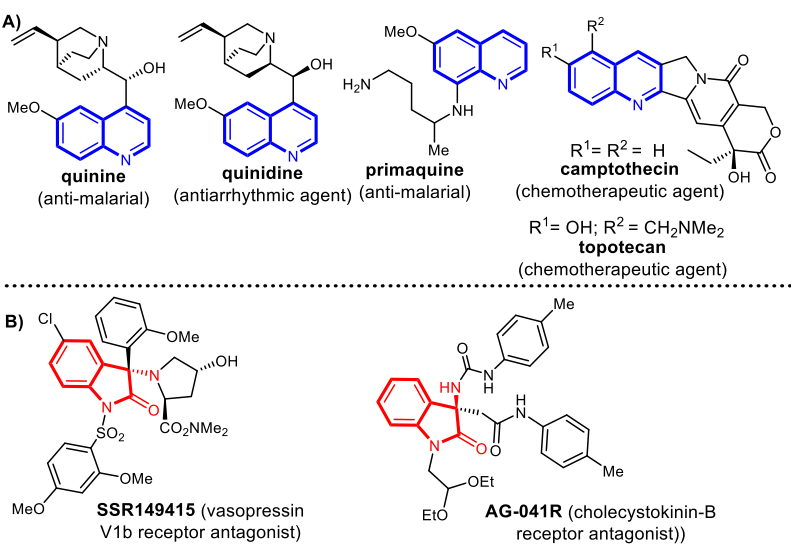

Figure 1. Examples of biologically active quinoline compounds and 3-substituted 3-amino-2-oxindoles.

However, this strategy has not been used for the enantioselective functionalization of hydroxyquinolines, to the best of our knowledge. In view of this, we decided to study the enantioselective aza-Friedel-Crafts reaction with imines, given the importance of the development of the asymmetric synthesis of chiral amines. ${ }^{[8]}$ Recently, an aza-FriedelCrafts reaction with 8-hydroxyquinoline has been described. However, this approach was reported for the synthesis of racemic Betti bases. ${ }^{[9]}$ In this 
communication, we have chosen Boc-protected isatinderived ketimines as electrophiles, ${ }^{[10,11]}$ which provided enantioenriched tetrasubstituted 3aminooxindoles ${ }^{[12]}$ Remarkably, this motif is present in several biologically active compounds such as those shown in Figure 1B. ${ }^{[13,14]}$ As a part of our ongoing interest in the asymmetric synthesis of chiral tetrasubstituted 3 -aminooxindoles, ${ }^{[15]}$ herein we present the first enantioselective addition of hydroxyquinolines to isatin-derived ketimines catalyzed by a thiourea bifunctional organocatalyst.

We chose the reaction of 6-hydroxyquinoline 1a with isatin-derived $N$-Boc ketimine $\mathbf{2 a}$ as a model reaction to screen various bifunctional organocatalysts. Bifunctional organocatalyst have been choosen considering the significant advantages of this kind of catalyst in asymmetric catalysis, ${ }^{[16]}$ and we assume that the double-activation mode of hydrogen bonding and a Brønsted base could be essential to promote the azaFriedel-Crafts aminoalkylation of hydroxyquinolines.

Table 1. Optimization of the reaction conditions. ${ }^{\mathrm{a}}$

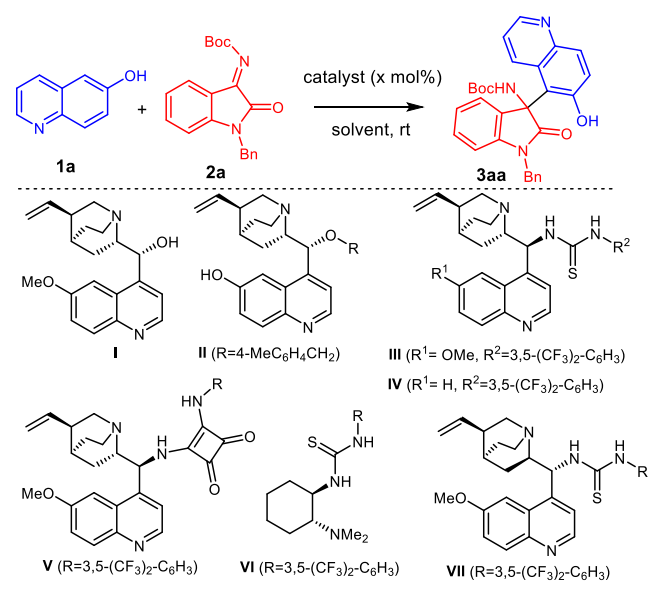

\begin{tabular}{|c|c|c|c|c|c|}
\hline Entry & $\begin{array}{l}\text { Cat. } \\
(\mathrm{x} \%)\end{array}$ & $\mathrm{t}(\mathrm{h})$ & Solv. & $\begin{array}{l}\text { Y. } \\
(\%)^{b}\end{array}$ & $\begin{array}{l}\text { ee } \\
(\%)^{\mathrm{c}}\end{array}$ \\
\hline 1 & I $(10 \%)$ & 95 & Tol. & 66 & 15 \\
\hline 2 & II $(5 \%)$ & 30 & Tol. & 15 & 89 \\
\hline 3 & III (5\%) & 45 & Tol. & 96 & 98 \\
\hline 4 & IV $(5 \%)$ & 29 & Tol. & 74 & 98 \\
\hline 5 & $\mathbf{V}(5 \%)$ & 22 & Tol. & 55 & 99 \\
\hline 6 & VI $(5 \%)$ & 24 & Tol. & 56 & $93^{\mathrm{d}}$ \\
\hline 7 & III (5\%) & 45 & EtOAc & 94 & 95 \\
\hline 8 & III (5\%) & 45 & THF & 58 & 93 \\
\hline 9 & III $(5 \%)$ & 45 & $\mathrm{CH}_{2} \mathrm{Cl}_{2}$ & 90 & 92 \\
\hline 10 & III $(2 \%)$ & 45 & Tol. & 57 & 98 \\
\hline 11 & III ( $1 \%)$ & 45 & Tol. & 25 & 96 \\
\hline 12 & VII $(5 \%)$ & 45 & Tol. & 65 & $97^{\mathrm{d}}$ \\
\hline
\end{tabular}

a) Reaction conditions: $0.1 \mathrm{mmol} \mathrm{1a}, 0.1 \mathrm{mmol} \mathrm{2a}$, and catalyst in dry solvent $(1.5 \mathrm{~mL})$ at $\mathrm{rt} .{ }^{\text {b) }}$ Isolated yield after column chromatography, >20:1 regioselectivity determined by ${ }^{1} \mathrm{H}$ NMR. ${ }^{\text {c) }}$ Enantiomeric excess determined by chiral HPLC. ${ }^{\text {d) }}$ Opposite enantiomer.
Quinine (I) catalyzed the reaction to obtain the product 3aa with $66 \%$ yield after 6 days (Table 1, entry 1), however the product was obtained with low enantiomeric excess (15\% ee). When cupreine derivative II was used as catalyst high enantioselectivity $(89 \%$ ee) was obtained, but the yield was very low ${ }^{[17]}(15 \%$, Table 1 , entry 2$)$. To our delight, when quinine-derived thiourea III was used (Table 1, entry 3 ), the reaction proceeded smoothly with excellent results. The chiral quinoline 3aa was obtained with $96 \%$ yield and $98 \%$ ee, after 2 days. When cinchonidine-derived thiourea IV was tested as catalyst, product 3aa was afforded with the same enantiomeric excess but lower yield (74\%). The reaction with quinine-derived squaramide $\mathbf{V}$, gave excellent enantioselectivity ( $99 \%$ ee), although with moderate yield $(56 \%) .{ }^{[17]}$ Other thiourea organocatalyst bearing a tertiary amine moiety, such as Takemoto's catalyst VI, proved to be an efficient catalyst in terms of enantioselectivity $(93 \% e e)$, though with a decreased yield (Table 1, entry 6). Therefore we chose catalyst III to continue further optimization. Other solvents such as EtOAc, THF or $\mathrm{CH}_{2} \mathrm{Cl}_{2}$, were also screened, but slightly lower enantioselectivities were observed (entries 7-9). The aza-Friedel-Crafts product 3aa could be also achieved with good enantiomeric excess when only 2 or $1 \mathrm{~mol} \%$ of catalyst was used (entry 10 and 11, respectively), although with lower yields. Furthermore, the opposite enantiomer of 3aa, was achieved with excellent enantioselectivity ( $97 \%$ ee, entry 12 ), when quinidinederived thiourea VII (5 mol\%) was used as a catalyst.
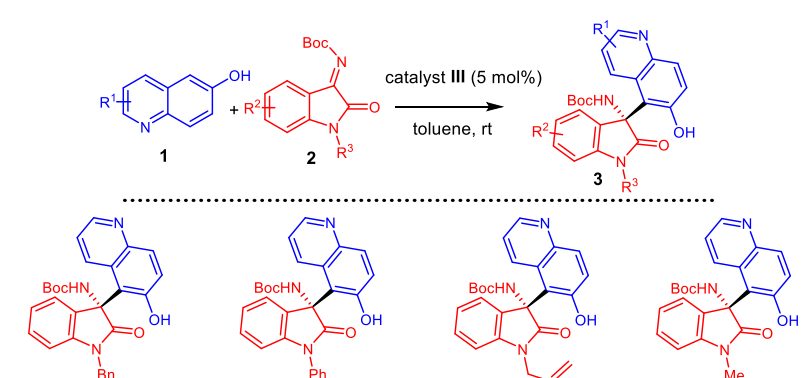
3aa, $96 \%$ yield, $98 \%$ ee $\quad 3$ ab, $73 \%$ yield, $94 \%$ ee $\quad 3$ 3ac, $65 \%$ yield, $95 \%$ ee 3 3ad, $77 \%$ ye yield, $95 \%$

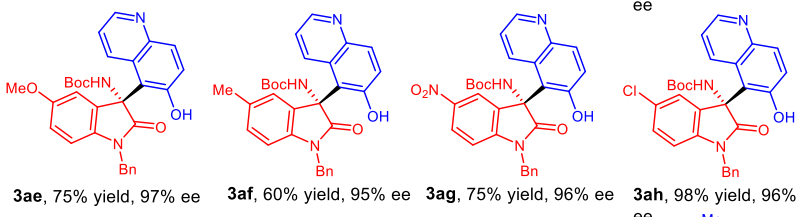

3ae, $75 \%$ yield, $97 \%$ ee $\quad$ 3af, $60 \%$ yield, $95 \%$ ee 3 3ag, $75 \%$ yield, $96 \%$ ee $\quad$ 3ah, $98 \%$ yield, $96 \%$

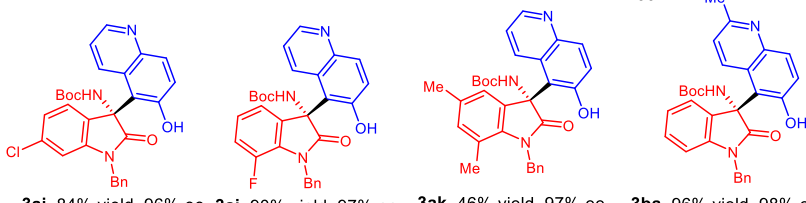

3ai, $84 \%$ yield, $96 \%$ ee 3 aj, $90 \%$ yield, $97 \%$ ee $\quad 3$ ak, $46 \%$ yield, $97 \%$ ee 3 ba, $96 \%$ yield, $98 \%$ ee

Scheme 1. Scope of the aza-Friedel-Crafts reaction of 6hydroxyquinolines with 2 . Reaction conditions: 1 (0.1 mmol), 2 (0.1 mmol), and catalyst III (5 mol\%) in dry toluene $(1 \mathrm{~mL})$ at $\mathrm{rt}$ for $45 \mathrm{~h}$. Isolated yield after column chromatography, >20:1 regioselectivity determined by ${ }^{1} \mathrm{H}$ NMR. 
With the optimized reaction conditions in hand (entry 3 , Table 1), we proceeded to study the scope of the azaFriedel-Crafts reaction of 6-hydroxyquinolines with ketimines 2 (Scheme 1). Initially, substitution at the N1 of the oxindole was evaluated (Scheme 1, 3 aa3 ad). Groups such as benzyl, phenyl, allyl or methyl were well tolerated, providing the corresponding products with high enantioselectivities $(94-98 \% e e)$. Next, we evaluated different $N$-Boc ketimines derived from various substituted $N$-benzylisatines. Electrondonating $(\mathrm{MeO}$ or $\mathrm{Me})$ or electron-withdrawing $\left(\mathrm{NO}_{2}\right.$ or $\mathrm{Cl}$ ) groups were tolerated at the 5-position of the isatin-derived ketimine, affording the corresponding products (3ae-3ah) with good yields and high enantioselectivities. Moreover, ketimines with substituents at 6- or 7-positions reacted smoothly, providing the aminoalkylated hydroxyquinolines 3ai and 3aj with good results. Moreover, the disubstituted ketimine $\mathbf{2 k}$ could be used, obtaining the corresponding product 3ak with excellent enantiomeric excess (97\%), but moderate yield (46\%). 6-hydroxyquinaldine $\mathbf{1 b}$ could also be applied under the optimized reaction conditions giving $3 \mathbf{b a}$ with excellents results (96\% yield, $98 \%$ ee).

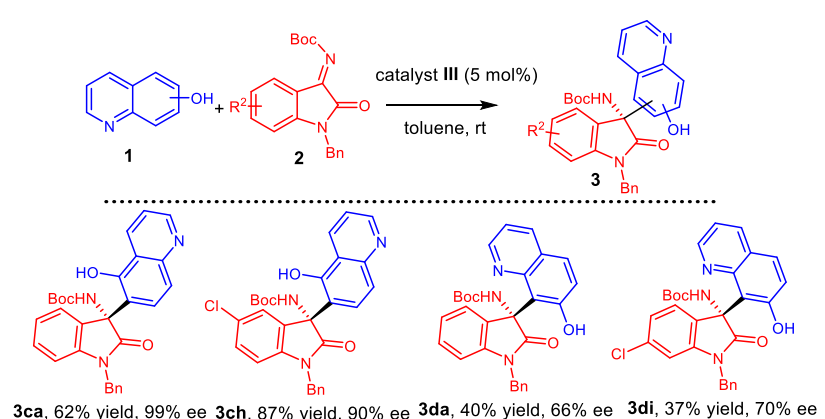

Scheme 2. Scope of the aza-Friedel-Crafts reaction of hydroxyquinolines with 2 . Reaction conditions: $1(0.1$ $\mathrm{mmol}), 2$ (0.1 mmol), and catalyst III (5 mol\%) in dry toluene $(1.5 \mathrm{~mL})$ at $\mathrm{rt}$ for $45 \mathrm{~h}$. Isolated yield after column chromatography, >20:1 regioselectivity determined by ${ }^{1} \mathrm{H}$ NMR.

After have proved the efficiency of our methodology for the enantioselective aza-Friedel-Crafts alkylation of 6-hydroxyquinoline at the C-5 position of the carbocyclic ring, we studied the scope of the reaction with other hydroxyquinolines bearing a hydroxy group in other positions of the carbocyclic ring (Scheme 2). Our goal was to achieve the enantioselective functionalization of every position in this ring by simply changing the position of the directing group. When 5-hydroxyquinoline (1c) was used as nucleophile under the optimized reaction conditions, with ketimine $\mathbf{2 a}$ and $\mathbf{2 h}$, products $\mathbf{3 c a}$ and $\mathbf{3 c h}$, substituted at C-6 were obtained with good yields and high enantiomeric excesses. 7-Hydroxyquinoline (1d) was also applied, although we observed a diminished reactivity and enantioselectivity. The 7hydroxyquinoline was regioselectively alkylated at C-
8, with ketimines $\mathbf{2 a}$ and $\mathbf{2 i}$, with moderate yields and moderate enantiomeric excesses. Finally, when 8hydroxyquinoline was used as nucleophile, we could not observed any reaction products. We attribute the lack of the reactivity of 8-hydroxyquinoline to an intramolecular hydrogen bonding between the hydroxyl group and the nitrogen atom from the quinoline.

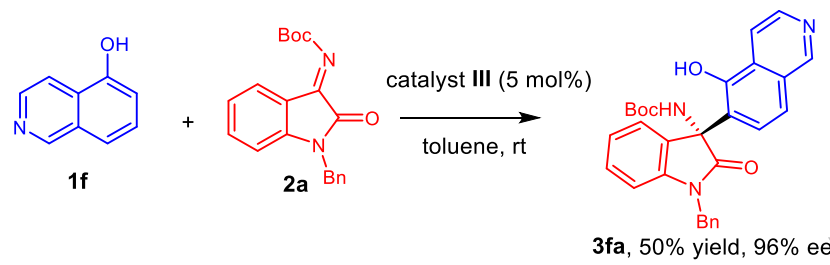

Scheme 3. Aza-Friedel-Crafts reaction of 5 hydroxyisoquinolines with 2a. Reaction conditions: 1f $(0.1$ $\mathrm{mmol})$, $2 \mathbf{a}(0.1 \mathrm{mmol})$, and catalyst III $(5 \mathrm{~mol} \%)$ in dry toluene $(1 \mathrm{~mL})$ at $\mathrm{rt}$ for $45 \mathrm{~h}$. Isolated yield after column chromatography, >20:1 regioselectivity determined by ${ }^{1} \mathrm{H}$ NMR.

Isoquinoline scaffold is also an important nitrogen heterocycle that is present in a wide range of natural products and pharmaceuticals. ${ }^{[18]}$ In view of the importance of isoquinoline structure, we decided to explore our methodology with the aza-Friedel-Crafts reaction of a hydroxyisoquinoline, in order t enantioselectively functionalize the carbocylic ring. Thus, 5-hydroxyisoquinoline $\mathbf{1 f}$ was used as nucleophile under the optimized reaction conditions (Scheme 3), and the corresponding product 3fe, regioselectively alkylated at C-6, was obtained with an excellent $96 \%$ ee, but moderate yield (50\%).

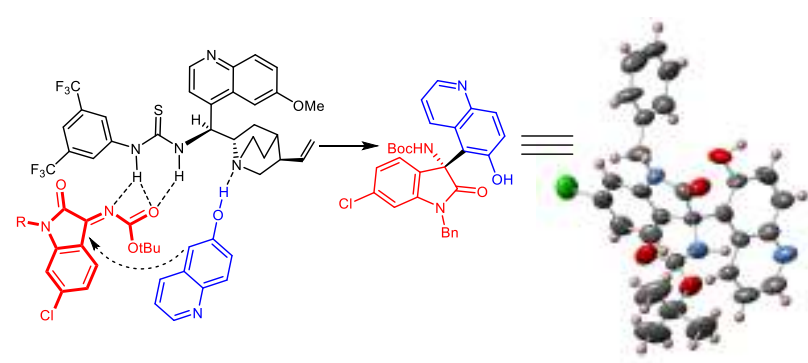

Scheme 4. Plausible transition-state model and X-ray crystal structure of $\mathbf{3 a i}$.

The absolute configuration of the stereogenic centre in compound 3ai was determined to be $(R)$ on the basis of X-ray crystallographic analysis (Scheme 4); the configuration of the rest of the products $\mathbf{3}$ were assigned on the assumption of a uniform mechanistic pathway. ${ }^{[19]}$ A plausible transition-state model is depicted in Scheme 4. The thiourea catalyst is the responsible for the preorientation and the activation of 
the substrates acting as bifunctional organocatalyst. While the isatin-derived $N$-Boc-ketimine is activated upon formation of hydrogen bonds between the $N$-Boc group and the thiourea moiety of the catalyst, the hydroxyquinoline undergoes nucleophilic activation by hydrogen bonding with the quinuclidine moiety of the catalyst, as Khan and Ganguly propose for the addition of naphthols to the same ketimines. ${ }^{[20,21]}$ The quinoline will be directed to the $R e$-face of the ketimine, thus accounting for the observed enantioselectivity.

Additionally, different synthetic transformations were conducted with compound 3aa, proving the utility of the developed methodology (Scheme 5). Compound 3aa was transformed into triflate $\mathbf{4}$ with good yield preserving the enantiomeric purity. Hydroxyquinoline derivative 3aa was also easily transformed into $\mathrm{N}$ oxide 5 by oxidation with $m$-CPBA in $\mathrm{CH}_{2} \mathrm{Cl}_{2}$. Finally, removal of the Boc group in 3aa was achieved by heating in acetic acid at $60^{\circ} \mathrm{C}$ affording the free amine 6 in $95 \%$ yield without loss of the stereochemical purity.

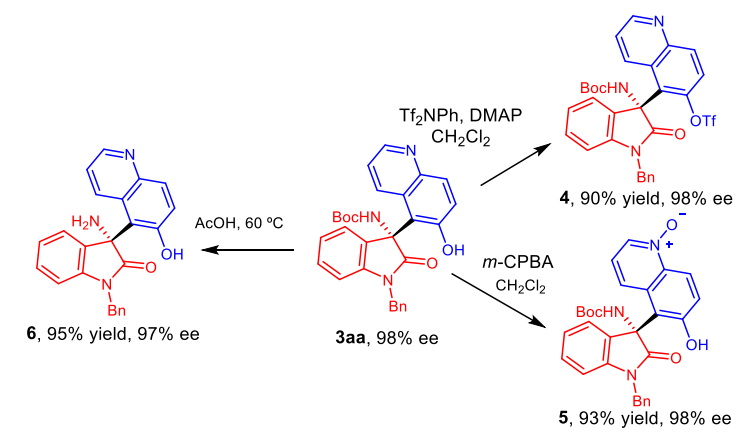

Scheme 5. Synthetic transformations.

In conclusion, we have developed an enantioselective aza-Friedel-Crafts reaction of hydroxyquinolines ${ }^{[22]}$ with isatin-derived ketimines, ${ }^{[23]}$ using a quininederived thiourea organocatalyst, obtaining the corresponding chiral 3-aminooxindoles with good yields and excellent enantioselectivities (up to 99\% ee). This approach enables the introduction of substituents in positions C-5, C- 6 or C-8 of the carbocyclic ring of quinoline in a regioselective manner, by just switching the position of the activating/directing hydroxy group. Furthermore, 5-hydroxyisoquinoline was enantioselectively alkylated with good results. Moreover, several transformations have been carried out with the products obtained. We envision that this procedure provides a successfully approach for the enantioselective functionalization of the carbocyclic ring of quinolines.

\section{Experimental Section}

General procedure for the enantioselective aza-FriedelCrafts of hydroxyquinolines 1 and ketimines 2
In a $10 \mathrm{~mL}$ round bottom flask, hydroxyquinoline $\mathbf{1}(14.5$ $\mathrm{mg}, 0.1 \mathrm{mmol})$, ketimine $2(0.1 \mathrm{mmol})$, catalyst III $(3.0 \mathrm{mg}$, $0.005 \mathrm{mmol}, 0.05 \mathrm{eq}$ ) and a stir bar were placed. The flask was purged with $\mathrm{N}_{2}$ and toluene $(1 \mathrm{~mL})$ was added via syringe. The mixture was stirred at room temperature until completion (TLC). Finally, the reaction mixture was directly poured into a column for chromatography, using hexane:EtOAc or $\mathrm{CH}_{2} \mathrm{Cl}_{2}: \mathrm{MeOH}$ as eluents to afford product 3.

\section{Synthesis and characterization data for compound 4}

Compound 3aa (48.1 $\mathrm{mg}, \quad 0.1 \mathrm{mmol})$ and 4dimethylaminopyridine $(36.8 \mathrm{mg}, 0.3 \mathrm{mmol}, 3 \mathrm{eq})$ were placed in a $10 \mathrm{~mL}$ round bottom flask. Then, the flask was purged with $\mathrm{N}_{2}$ and $\mathrm{CH}_{2} \mathrm{Cl}_{2}(1 \mathrm{~mL})$ was added. After 5 minutes, $N$-phenyl-bis(trifluoromethanesulfonimide (71.5 $\mathrm{mg}, 0.2 \mathrm{mmol}, 2 \mathrm{eq}$ ) was added and the mixture was stirred at room temperature. The reaction was monitored by TLC. When the starting material was consumed, $\mathrm{H}_{2} \mathrm{O}$ was added $(5 \mathrm{~mL})$ and the mixture was extracted with EtOAc $(3 \times 20$ $\mathrm{mL})$. The combined organic layers were washed with brine $(30 \mathrm{~mL})$ and dried under anhydrous $\mathrm{Na}_{2} \mathrm{SO}_{4}$. The organic solvents were removed under reduced pressure and the residue was purified by column chromatography being eluted with hexane: AcOEt (90:10 to 60:40).

\section{Synthesis and characterization data for compound 5}

Compound 3aa (48.1 mg, $0.1 \mathrm{mmol})$ and metachloroperoxybenzoic acid $(17.3 \mathrm{mg}, 0.2 \mathrm{mmol})$ were dissolved in $1 \mathrm{~mL}$ of $\mathrm{CH}_{2} \mathrm{Cl}_{2}$ and the mixture was stirred at room temperature. The reaction was monitored by thin layer chromatography being eluted with hexane:AcOEt. When the starting material was consumed, the solvent was removed, and the crude mixture was dissolved in $\mathrm{CH}_{2} \mathrm{Cl}_{2}$ and poured directly to the column chromatograpy, using hexane:AcOEt (90:10 to 60:40)as eluent to afford product 5 .

\section{Synthesis and characterization data for compound 6}

Compound 3aa (40 mg, $0.08 \mathrm{mmol}$ ) was dissolved in $\mathrm{AcOH}$ $(2 \mathrm{~mL})$. The solution was stirred at $60^{\circ} \mathrm{C}$ until completion. Then, the reaction was quenched with a saturated aquou. $\mathrm{NaHCO}_{3}$ solution and extracted with $\mathrm{CH}_{2} \mathrm{Cl}_{2}(3 \times 30 \mathrm{~mL})$. After drying the organic phase over $\mathrm{MgSO}_{4}$ and evaporation of the solvent, the residue was purified by column chromatography being eluted with $\mathrm{CH}_{2} \mathrm{Cl}_{2}$ : MeOH (100:0 to 95:5).

\section{Acknowledgements}

Financial support from the MINECO (Gobierno de España; CTQ2013-47494-P) is gratefully acknowledged. C.V. thanks MINECO for a JdC contract and M.M-M. thanks Universitat de València for a pre-doctoral grant. Access to NMR, MS and X-ray facilities from the Servei central de suport a la investigacio experimental (SCSIE)-UV is also acknowledged.

\section{References}

[1] a) Ring Nitrogen and Key Biomolecules: The Biochemistry of $\mathrm{N}$-Heterocycles, Ed.: E.G. Brown, Springer, 1998; b) Modern Heterocyclic Chemistry, Ed.: J. Alvarez-Builla, J. J. Vaquero, J. Barluenga, WileyVCH, Weinheim, 2011; c) Heterocyclic Chemistry, Ed.: J. A. Joule, K. Mills, Wiley, Chichester, 2010.

[2] a) R. H. Manske, Chem. Rev., 1942, 30, 113-144; b) S. M. Prajapati, K. D. Patel, R. H. Vekariya, S. N. Panchal, H. D. Patel, RSC Adv., 2014, 4, 24463-24475; c) A. Marella, O. P. Tanwar, R. Saha, M. R. Ali, S. Srivastava, 
M. Akhter, M. Shaquiquzzaman, M. M. Alam, Saudi Pharm. J. 2013, 21, 1-12.

[3] J. P. Michael, Nat. Prod. Rep., 2008, 25, 166-187.

[4] T. Iwai, M. Sawamura, ACS Catal., 2015, 5, 5031-5040.

[5] Selected examples: a) M. Rueping, A. P. Antonchick, T. Theissmann, Angew. Chem. Int. Ed. 2006, 45, 36833686, Angew. Chem. 2006, 118, 3765-3768; b) T. Fischer, Q.-N. Duong, O. García-Mancheño, Chem. Eur. J. 2017, 23, 5983-5987; c) M. Zurro, S. Asmus, S. Beckendorf, C. Mück-Lichtenfeld, O. GarcíaMancheño, J. Am. Chem. Soc. 2014, 136, 13999-14002; d) Y. Yamaoka, H. Miyabe, Y. Takemoto, J. Am. Chem. Soc. 2007, 129, 6686-6687; e) M. Takamura, K. Funabashi, M. Kanai, M. Shibasaki, J. Am. Chem. Soc. 2000, 122, 6327-6328; f) D. A. Black, R. E. Beveridge, B. A. Arndtsen, J. Org. Chem. 2008, 73, 1906-1910; g) M. Pappoppula, F. S. P. Cardoso, B. O. Garrett, A. Aponick, Angew. Chem. 2015, 127, 15417-15421; Angew. Chem. Int. Ed. 2015, 54, 15202-15207; h) C. M. R. Volla, E. Fava, I. Atodiresei, M. Rueping, Chem. Commun., 2015, 51, 15788-15791; i) J. D. Shields, D. T. Ahneman, T. J. A. Graham, A.l G. Doyle, Org. Lett., 2014, 16, 142-145; j) T. Kodama, P. N. Moquist, S. E. Schaus, Org. Lett., 2011, 13, 6316-6319; k) S. Sun, Y. Mao, H. Lou, L. Liu, Chem. Commun., 2015, 51, 1069110694; 1) F. Berti, F. Malossi, F. Marchetti, M. Pineschi, Chem. Commun., 2015, 51, 13694-13697; m) M. Rueping, T. Theissmann, M. Stoeckel, A. P. Antonchick, Org. Biomol. Chem. 2011, 9, 6844-6850; n) M. Rueping, T. Theissmann, Chem. Sci. 2010, 1, 473-476.

[6] M. Montesinos-Magraner, C. Vila, G. Blay, J. R. Pedro, Synthesis, 2016, 48, 2151-2164.

[7] S. Brandes, B. Niess, M. Bella, A. Prieto, J. Overgaard, K. A. Jørgensen, Chem. Eur. J. 2006, 12, 6039-6052.

[8] Chiral Amine Synthesis: Methods, Developments and Applications, Ed.: T. C. Nugent, Wiley-VCH, Weinheim, 2010.

[9] C. C. Thinnes, A. Tumber, C. Yapp, G. Scozzafava, T. Yeh, M. C. Chan, T. A. Tran, K. Hsu, H. Tarhonskaya, L. J. Walport, S. E. Wilkins, E. D. Martinez, S. Müller, C. W. Pugh, P. J. Ratcliffe, P. E. Brennan, A. Kawamura, C. J. Schofield, Chem. Commun., 2015, 51, 1545815461 .

[10] For selected examples of enantioselective reactions using isatin-derived ketimines as electrophiles, see: a) J. Feng, W. Yan, D. Wang, P. Li, Q. Sun, R. Wang, Chem. Commun. 2012, 48, 8003-8005; b) J. Zhao, B. Fang, W. Luo, X. Hao, X. Liu, L. Lin, X. Feng, Angew. Chem. 2015, 127, 243-246; Angew. Chem. Int. Ed. 2015, 54, 241-244; c) O. D. Engl, S. P. Fritz, H. Wennemers, Angew. Chem. 2015, 127, 8311-8315; Angew. Chem. Int. Ed. 2015, 54, 8193-8197; d) D. Wang, J. Liang, J. Feng, K. Wang, Q. Sun, L. Zhao, D. Li, W. Yan, R. Wang, Adv. Synth. Catal. 2013, 355, 548-558; e) T. Arai, E. Matsumura, H. Masu, Org. Lett. 2014, 16, 2768-2771; f) S. Nakamura, K. Hyodo, M. Nakamura, D. Nakane, H. Masuda, Chem. Eur. J. 2013, 19, 7304-7309; g) J. Feng, W. Yan, D. Wang, P. Li, Q. Sun, R. Wang, Chem.
Commun. 2012, 48, 8003-8005; h) K. Zhao, T. Shu, J. Jia, G. Raabe, D. Enders, Chem. Eur. J. 2015, 21, 39333936; i) J. Xu, C. Mou, T. Zhu, B.-A. Song, Y. R. Chi, Org. Lett. 2014, 16, 3272-3275; j) N. Hara, S. Nakamura, M. Sano, R. Tamura, Y. Funahashi, N. Shibata, Chem. Eur. J. 2012, 18, 9276-9280; k) K. Zhao, Y. Zhi, X. Li, R. Puttreddy, K. Rissasen, D. Enders, Chem. Commun. 2016, 52, 2249-2252.

[11] For selected organocatalytic enantioselective FriedelCrafts reactions with other ketimines, see: a) Y.-X. Jia, J. Zhong, S.-F. Zhu, C.-M. Zhang, Q.-L. Zhou, Angew. Chem. 2007, 119, 5661-5663; Angew. Chem. Int. Ed. 2007, 46, 5565-5567; b) R. Husmann, E. Sugiono, S. Mersmann, G. Raabe, M. Rueping, C. Bolm, Org. Lett. 2011, 13, 1044-1047; c) K.-F. Zhang, J. Nie, R. Guo, Y. Zheng, J.-A. Ma , Adv. Synth. Catal. 2013, 355, $3497-$ 3502; d) T. Kano, R. Takechi, R. Kobayashia, K. Maruoka, Org. Biomol. Chem., 2014, 12, 724-727; e) L. Wu, R.-R.Liu, G. Zhang, D.-J.Wang, H. Wu, J. Gao, Y.X. Jia, Adv. Synth. Catal. 2015, 357, 709-713; d) S. Nakamura, N. Matsuda, M. Ohara, Chem. Eur. J. 2016, 22, 9478-9482.

[12] For a review in the synthesis of chiral 3aminooxindoles: a) P. Chauhan, S. S. Chimni, Tetrahedron: Asymmetry 2013, 24, 343-356; b) J. Kaur, S. S. Chimni, S. Mahajan, A. Kumar, RSC Adv. 2015, 5 , 52481-52496; c) J.-S. Yu, F. Zhou, Y.-L. Liu, J. Zhou, Synlett 2015, 26, 2491-2504.

[13] a) K. Bernard, S. Bogliolo, J. B. Ehrenfeld, Br. J. Pharmacol., 2005, 144, 1037-1050; b) T. Oost, C Backfisch, S. Bhowmik, M. M. van Gaalen, H. Geneste, W. Hornberger, W. Lubisch, A. Netz, L. Unger, W Wernet, Bioorg. Med. Chem. Lett., 2011, 21, 3828-3831. c) G. Decaux, A. Soupart, G. Vassart, Lancet 2008, 371 . 1624-1632. d) T. Shimazaki, M. Iijima, S. Chaki, Eur. J. Pharmacol. 2006, 543, 63-67.

[14] M. Ochi, K. Kawasaki, H. Kataoka, Y. Uchio, H. Nishi, Biochem. Biophys. Res. Commun., 2001, 283, 11181123.

[15] a) M. Holmquist, G. Blay, J. R. Pedro, Chem. Commun. 2014, 50, 9309-9312; b) M. Montesinos-Magraner, C. Vila, R. Cantón, G. Blay, I. Fernández, M. C. Muñoz, J. R. Pedro, Angew. Chem. 2015, 127, 6418-6422; Angew. Chem. Int. Ed. 2015, 54, 6320-6324; c) M. Holmquist, G. Blay, M. C. Muñoz, J. R. Pedro, Adv. Synth. Catal. 2015, 357, 3857-3862; d) C. Vila, F. I. Amr, G. Blay, M. C. Muñoz, J. R. Pedro, Chem. Asian J. 2016, 11, 1532 1536; e) F. I. Amr, C. Vila, G. Blay, M. C. Muñoz, J. F Pedro, Adv. Synth. Catal., 2016, 358, 1583-1588; f) M. Montesinos-Magraner, C. Vila, A. Rendón-Patiño, G. Blay, I. Fernández, M. C. Muñoz, J. R. Pedro, ACS Catal., 2016, 6, 2689-2693.

[16] a) S.-K. Tian, Y.-G. Chen, J. F. Hang, L. Tang, P. McDaid, L. Deng, Acc. Chem. Res. 2004, 37, 621-631; b) Y. Takemoto, Org. Biomol. Chem. 2005, 3, 42994306; c) S. Connon, Chem. Eur. J. 2006, 12, 5418-5427; d) A. G. Doyle, E. N. Jacobsen, Chem. Rev. 2007, 107, 5713-5743; e) T. Marcelli, H. Hiemstra, Synthesis 2010, 
1229-1279; f) J. Aleman, A. Parra, H. Jiang, K. A. Jørgensen, Chem. Eur. J. 2011, 17, 6890-6899.

[17] The lower yields are due to the hydrolysis of the isatinderived ketamine under the reaction conditions.

[18] a) T. Eicher, S. Hauptmann, A. Speicher, The Chemistry of Heterocycles, Structure, Reactions, Synthesis and Applications; Wiley-VCH: Weinheim, 2003; b) K. W. Bentley, Robert Robinson, The Isoquinoline Alkaloids, Pergamon Press, 1965; b) K. W. Bentley, Nat. Prod. Rep., 1992, 8, 365-391; c) M. Chrzanowska, A. Grajewska, M. D. Rozwadowska, Chem. Rev., 2016, 116, 12369-12465.

[19] CCDC 1557026 (3ai) contains the supplementary crystallographic data for this paper. These data can be obtained free of charge from The Cambridge Crystallographic Data Centre via www.ccdc.cam.ac.uk/data request/cif.
[20] P. Kumari, S. Barik, N. H. Khan, B. Ganguly, R. I. Kureshy, S. H. R. Abdiab, H. C. Bajaj, RSC Adv. 2015, 5, 69493-69501.

[21] 6-methoxyquinoline was unreactive under the reaction conditions, proving that the hydrogen bonding is essential for the activation of the nucleophile.

[22] We have tried the reaction with a cuprein derivative as nucleophile under the optimized reaction conditions. However we did not observe conversion to aza-FriedelCrafts product. See Supporting Information for further details.

[23] We have tried the reaction with other activated ketimines under the optimized reaction conditions. However we did not observed the aza-Friedel-Crafts reaction. See Supporting Information for further details. 


\section{COMMUNICATION}

Organocatalytic Enantioselective Functionalization of Hydroxyquinolines through an aza-FriedelCrafts Alkylation with Isatin-derived Ketimines

Adv. Synth. Catal. Year, Volume, Page - Page

Carlos Vila, ${ }^{a *}$ Alejandra Rendón-Patiño, ${ }^{\mathrm{a}}$ Marc

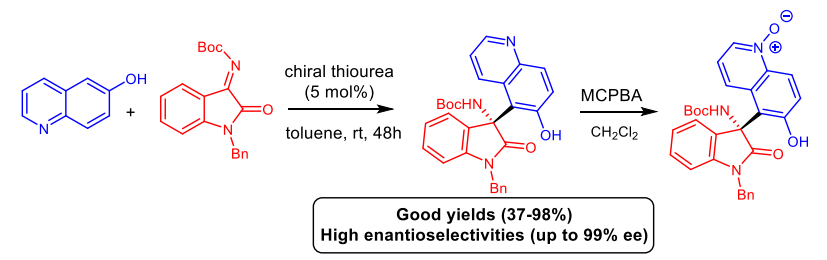

Montesinos-Magraner, ${ }^{\mathrm{a}}$ Gonzalo Blay, ${ }^{\mathrm{a}} \mathrm{M}$. Carmen

Muñoz ${ }^{b}$ and José R. Pedro ${ }^{a *}$ 